\title{
Female labor supply as insurance against idiosyncratic risk
}

\author{
Orazio Attanasio, University College London and IFS \\ Hamish Low, University of Cambridge and IFS \\ Virginia Sánchez-Marcos, Universidad de Cantabria
}

November 2004

\section{Introduction}

When a household is hit by a negative shock, for instance to the earnings of the main earner, it has several mechanisms through which such a shock may be absorbed and a reduction in consumption prevented. The most obvious is a reduction in savings (or the use of borrowing, if that is available). There might be several types of transfers and insurance mechanisms, either private or public. Finally, the household might change the composition of overall consumption, between non durables, durables and leisure. A reduction in leisure is particularly interesting because it implies an increase in income and because it might have other dynamic consequences through human capital.

In this paper, we explore the role of female labor supply as an insurance mechanism against idiosyncratic earnings risk within the family. To perform such an exercise we use a life cycle model in which a unitary family makes consumption, saving and labour supply decisions. The model is a complex one in which female participation decisions have important dynamic implications for female human capital. We have used this model in Attanasio, Low and Sanchez (2004) (ALS) to explain the increase in female labour force participation in the US during the last 30 years. Here we use it to quantify the welfare cost of an increase in idiosyncratic and uninsured uncertainty and to show the additional cost of uncertainty when female employment decisions are not allowed. The ability to make labor supply decisions mitigates the welfare cost of uncertainty.

This paper is related to several others. Low (2002) and Pijoan (2003) have looked at the self-insurance role that can be played by labour supply. The welfare cost of uncertainty has been studied, in different contexts by Lucas (1987), Attanasio and Davis (1996), Storesletten, Telmer and Yaron (2001). Rogerson and Schindler (2002) look at the welfare cost of unemployment shocks. Kotlikoff and Spivak (1981) conider the risk-sharing role played by the family.Finally, Gruber and Cullen (2000) check whether unemployment insurance reduces female labour supply, that is whether public insur- 
ance substitutes out the potential insurance role of female labour supply that we are investigating.

The rest of the paper is organized as follows. In Section 2 we describe the baseline model and discuss how to measure the extent to which female labour supply is used as an insurance mechanism. In Section 3 we describe the welfare consequences of increasing uncertainty in the baseline model. Section 4 contains the core results of the paper, while section 5 concludes with a discussion of possible extensions and directions of future research.

\section{The model}

In ALS, we have constructed a partial equilibrium life cycle model where a generic unitary household chooses consumption, saving and female labour supply to maximize expected utility. We used that model to explain the changes in female labour supply across different cohorts. The details of the model are discussed at length in ALS. Here we list its main features.

\subsection{The baseline specification.}

The unitary household maximizes:

$$
\max _{c, P} V_{t}=E_{t} \sum_{s=t}^{T} \beta^{s-t} u\left(c_{s}, P_{s}\right)
$$

subject to

$$
A_{t+1}=R\left(A_{t}+\left(y_{t}-F\left(a_{t}\right)\right) P_{t}+y_{t}^{m}-c_{t}\right)
$$

where $c_{s}, P_{s}$ and are consumption and female participation at time $s, A_{t}$ are assets at time $t, y_{t}^{m}$ are male earnings, $y_{t}-F\left(a_{t}\right)$ female earnings net of the cost of children $F(a)$, which in turns depends on the age of children. $R$ is the rate of return on assets, while $\beta$ is the discount factor.

The process for male earnings is exogenously given by a standard permanent/transitory process in logs.

$$
\begin{aligned}
\ln y_{t}^{m} & =\ln y_{0}^{m}+h_{t}^{m}+v_{t}^{m}+\varepsilon_{t}^{m} \quad \text { where } \varepsilon_{t}^{m} \sim N\left(-\frac{\sigma_{\varepsilon, m}^{2}}{2}, \sigma_{\varepsilon, m}^{2}\right) \\
v_{t}^{m} & =v_{t-1}^{m}+\xi_{t}^{m} \quad \text { where } \xi_{t}^{m} \sim N\left(-\frac{\sigma_{\xi, m}^{2}}{2}, \sigma_{\xi, m}^{2}\right) \\
h_{t}^{m} & =h_{t-1}^{m}+\left(\eta_{0}+\eta_{1} t\right)
\end{aligned}
$$


Notice that the process of human capital accumulation is completely deterministic in the case of males. The functional forms for the utility function and the cost of children are given by:

$$
\begin{gathered}
u\left(c_{t}, P_{t}\right)=\frac{\left(\frac{c_{t}}{e_{t}}\right)^{1-\gamma}}{1-\gamma} \exp \left(\psi_{1} P_{t}\right)-\psi_{2} P_{t} \\
G\left(a_{t}\right)=\theta \phi^{a_{t}-1} \quad \text { and } \quad F\left(a_{t}\right)=p G\left(a_{t}\right)
\end{gathered}
$$

In the instantaneous felicity function $u(.,$.$) , female participation discounts a isolastic$ function (defined in terms of consumption per adult equivalent) and has also a separable effect on consumption. Such a specification is not inconsistent with the available evidence. The functional form for the cost of children is chosen along the lines used by Altug and Miller (1988). The crucial feature of the model is the female earning process and its interaction with the (endogenous) process of human capital formation.

$$
\begin{gathered}
\ln y_{t}=\ln y_{0}+h_{t}+v_{t}+\varepsilon_{t} \quad \text { where } \varepsilon_{t} \sim N\left(-\frac{\sigma_{\varepsilon}^{2}}{2}, \sigma_{\varepsilon}^{2}\right) \\
v_{t}=v_{t-1}+\xi_{t} \quad \text { where } \xi_{t} \sim N\left(-\frac{\sigma_{\xi}^{2}}{2}, \sigma_{\xi}^{2}\right) \\
h_{t}=h_{t-1}+\left(\eta_{0}+\eta_{1} t\right) I\left(P_{t-1}=1\right)-\delta_{P} h_{t-1} I\left(P_{t-1}=0\right), \quad \eta_{0}>0, \eta_{1}<0
\end{gathered}
$$

The working of such a model are discussed in detail in ALS. Here it will suffice to notice the difference between this model and others models of female labour supply that have been used in the literature, such as Eckstein and Wolpin (1989) and van der Klaauw (1993). The models proposed in both these papers do not allow for borrowing or saving, so that consumption coincides with income. As discussed in ALS, this can be important for the behaviour of the model and its calibration. The human capital accumulation process we consider is in the spirit of Mincer and allows for a considerable degree of flexibility: it allows for different types of depreciations and for returns to experience. Finally, as discussed in ALS, the magnitude of the cost of children $p$, relative to female earnings, plays in this model a fundamental role, quantitatively more important than the dynamic issues implied by the complex model of human capital accumulation.

\subsection{Model calibration and simulation}

The baseline version of the model is calibrated as in ALS. In Table 1, we report the 'endogenous' parameters, while in Table 2, we report the calibration statistics. ${ }^{1}$

\footnotetext{
${ }^{1}$ We set the exogenous parameters as follows: $\sigma_{\xi}^{2}=0.031$ (Meghir and Pistaferri, 2003); $\theta=600$ and $\phi=0.89$ (Hotz and Miller, 1988); $\gamma=1.5$ (Attanasio and Weber, 1995); maternity age $k=24$ (PSID);
} 
Table 1: Model Parameters

\begin{tabular}{lc}
\hline \hline Endogenous Parameters & \\
\hline \hline Perm Depr, $\quad \delta_{P}$ & 0.03 \\
Child-care price, $\quad p$ & 14.0 \\
Utility Cost of Part, $\psi_{1}$ & 0.1 \\
Utility Cost of Part, $\psi_{2}$ & 0.001 \\
Returns to experience, $\eta_{0}$ & 0.065 \\
Returns to experience, $\eta_{1}$ & 0.00108 \\
\hline \hline
\end{tabular}

Table 2: Calibration

\begin{tabular}{lccc}
\hline \hline Variable & PSID & \multicolumn{2}{c}{ Model Predictions } \\
& & Unconstrained & $\begin{array}{c}\text { Borrowing } \\
\text { Constrained }\end{array}$ \\
\hline \hline Participation & 0.70 & 0.68 & 0.71 \\
Participation of mothers & 0.44 & 0.36 & 0.49 \\
Ratio before/after non participation & 1.80 & 2.74 & 2.04 \\
Median Duration out of labour force & 4 & 4 & 3 \\
\hline \hline
\end{tabular}

All the statistics used in Table 2 refer to the cohort of PSID women born in the 1940s. As discussed in ALS, the identification of all components of the model is not obvious and some of the parameters in Table 1 could be identified using different data moments. The chosen parameters, however, do a good job at matching the main features of life cycle participation behaviour of women born in the 1940s.

The numerical solution and simulation of the life cycle model we present is not a trivial matter and is discussed in ALS. There and in what follows, we consider three different versions of the model. In the first, and most general version of the model, households are allowed to save and borrow (at least to the point where they can pay back with probability one). In the second, households are only allowed to save, while in the third they cannot either save nor borrow. The last version of the model is similar to the one considered by, among others, Eckstein and Wolpin (1989) and van der Klaaw (1996).

and $\beta=0.98$ and $R=1.015$. 


\section{Increasing idiosyncratic earning uncertainty}

We start our exercise by studying the welfare cost of increasing the variance of idiosyncratic earnings (from a value of 0.031 to a value of 0.062). As discussed in ALS, the starting value for permanent uncertainty is already relatively high and corresponds to the upper end of available estimates. Almost doubling such a value probably yields an unrealistically high value for the variance of male earnings. The aim of this exercise, however, is not to construct a realistic simulation, but to stress the mechanisms at play within the model.

It should be stressed that the households in our model have no way to insure the type of shocks whose variance we are increasing. This is not unrealistic, as we are considering permanent shocks. The available evidence (see for instance, Attanasio and Davis, 1996 or Blundell, Pistaferri and Preston, 2004) indicates that most permanent shocks are reflected into consumption. On the contrary, transitory shocks, are by and large absorbed through changes in saving and borrowing (when this is allowed).

In Figures 1,2 and 3, corresponding to the three versions of the model, we report the average life cycle profile for the participation rates for the two levels of uncertainty considered. For the first two versions of the model we also report the average level of wealth accumulation by age.

The main features that emerge from the pictures are: (i) increasing uncertainty increases participation rates; (ii) the increase in concentrated in the last part of the life cycle and is virtually zero during child rearing ages; (iii) the effect is much smaller when the consumer has the ability of smoothing consumption over time through saving and borrowing. Even the possibility of saving only reduces the size of the effect relative to the case with no saving and borrowing.

Point (ii) above is consistent with the argument in ALS that intertemporal considerations have little effect in determining the labour supply of mothers for whom the main variable is the cost of children $p$. Point (iii) highlights that the size of the effect on participation depends on the amount of assets held: the response will be greater if households hold limited assets (or have limited further financial resources available) and so have to use female labor supply as insurance. If we are underestimating the amount of wealth in our baseline model, then we may be overestimating the effect on participation. $^{2}$

We are now ready to consider the welfare consequences of increasing uncertainty in the baseline model and in a version of the model where we remove the possibility of adjusting female labour supply.

\footnotetext{
${ }^{2}$ Median liquid asset holdings remain close to zero in the PSID until age 40. The subsequent rise in the data is faster than in our model, partly reflecting retirement which we do not have in our model. The difficulty is the extent to which retirement saving is liquid and can used for precautionary reasons.
} 


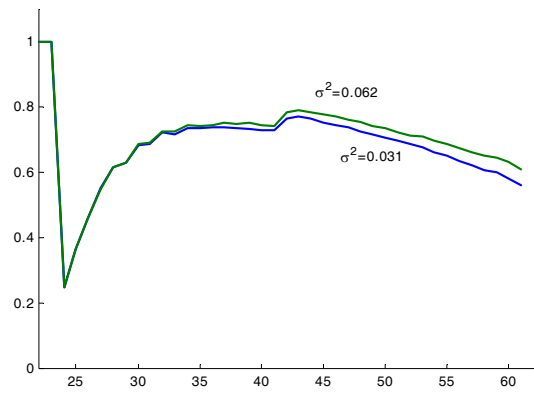

(a) Life-cycle Participation Profiles

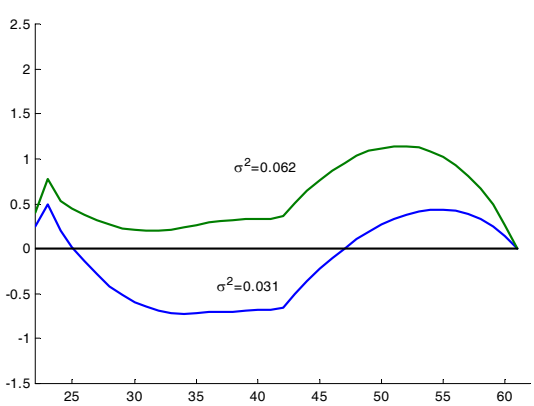

(b) Life-cycle Assets/Earnings Profiles

Figure 3.1: Unconstrained case

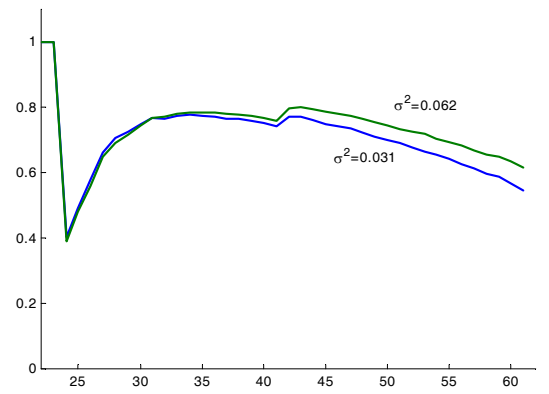

(a) Life-cycle Participation Profiles

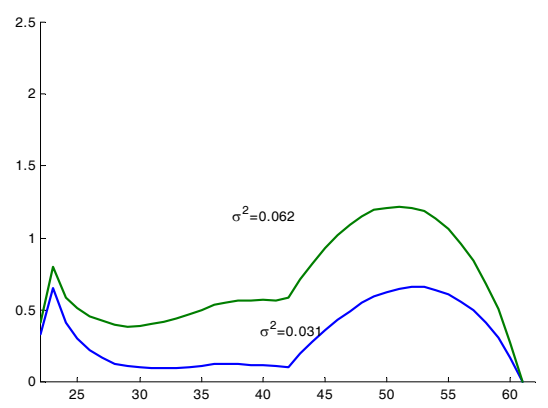

(b) Life-cycle Assets/Earnings Profiles Figure 3.2: Borrowing constrained case

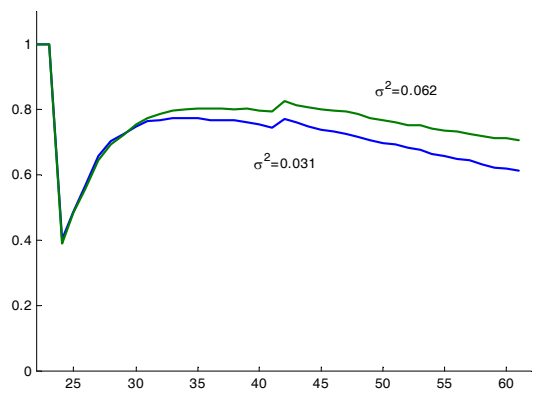

(a) Life-cycle Participation Profiles

Figure 3.3: Borrowing and saving constrained case 


\section{Welfare cost of uncertainty and female participation}

We calculate the welfare cost of uncertainty under different assumptions about labour supply choice and the household's ability to borrow. All results are collected in table 3 . We calculate $\pi$ as the amount of extra consumption households would need in order to compensate for the change of environment, where $\pi$ is defined implicitly by ${ }^{3}$

$$
E_{0}\left[\sum\left(\frac{1}{1-\gamma}\left(\frac{c_{t}(1+\pi)}{e_{t}}\right)^{1-\gamma} \exp \left(\psi_{1} P_{t}\right)-\psi_{2} P_{t}\right)\right]=\bar{U} .
$$

First we calculate the welfare cost of borrowing constraints. We use the scenario without borrowing constraints as the benchmark determining $\bar{U}$ and calculate $\pi$ for the no borrowing economy and for the no borrowing or saving economy. The cost of borrowing constraints of $0.6 \%$ of consumption is small relative to the cost of uncertainty.

Table 3: Welfare Costs

\begin{tabular}{|c|c|c|c|}
\hline & "Unconstrained & $\begin{array}{c}\text { Borrowing } \\
\text { Constrained }\end{array}$ & $\begin{array}{c}\text { Borrowing and } \\
\text { Saving Constrained }\end{array}$ \\
\hline $\begin{array}{c}\text { Borrowing constraints } \\
\text { I. } \\
\text { (Baseline }: \text { unconstrained })\end{array}$ & - & 0.60 & 2.64 \\
\hline \multicolumn{4}{|l|}{$\begin{array}{c}\text { Additional Uncertainty }{ }^{4} \\
\left.\text { II. Baseline }: \sigma^{2}=0.031\right)\end{array}$} \\
\hline a. With labor supply choice & 16.8 & 15.0 & 17.2 \\
\hline b. Without choice & 25.9 & 18.4 & 19.3 \\
\hline
\end{tabular}

Second, we calculate the welfare cost of additional uncertainty. The second row of Table 3 reports the welfare cost when women are able to vary labor supply in response to the extra uncertainty. Since this is a counterfactual experiment rather than using estimated changes in the variance, our focus is on the relative size of the welfare costs

\footnotetext{
${ }^{3}$ This consumption measure of the welfare cost ignores any change in welfare directly associated with changes in participation choices. In particular, increasing participation in response to increased uncertainty imposes a welfare cost which is not captured by $\pi$.

${ }^{4}$ The baseline $\bar{U}$ differs in each of the 6 cases. In each case the baseline is determined by the specified environment for borrowing and for labour supply, with a low varianceof husband earnings. Each number represents the cost of the extra uncertainty holding that environment constant.
} 
rather than their absolute values. The welfare cost of extra uncertainty is higher when unconstrained than when borrowing is constrained. Of course, expected utility is always higher in the unconstrained case for a given amount of uncertainty, but extra uncertainty reduces borrowing opportunities by reducing minimum lifetime income and this impacts only on those who were able to borrow in the baseline. Therefore, households lose more from the extra uncertainty when they had previously been able to borrow.

The final row of Table 3 reports the welfare cost when labour supply is restricted. There are a number of possible assumptions that could be made about the path of income and labor supply. We want to capture the cost of not being able to adjust labor supply to insure against the additional risk associated with the extra uncertainty. One assumption is that households receive an exogenous stream of stochastic income from female labour supply, where the stream of income is weighted by the average participation rates. Participation rates are age specific and can be taken from the realised paths for the low or high variance cases. An alternative assumption is that households are not permitted to change their labour supply decisions as uncertainty increases. We make the first assumption and report the cost of extra uncertainty when households receive an exogenous income stream. ${ }^{5}$ The first point is that the lack of ability to adjust labour supply in response to the greater uncertainty increases the welfare cost. The second point is that the increase in the welfare cost is greater when borrowing is unconstrained. This suggests a complementarity between flexibility in labor markets and flexibility in borrowing and saving.

\section{Conclusions and future research}

In this paper we have analyzed the role that female labour supply can play as an insurance mechanism against shocks to future earnings. The evidence we have presented points to a potentially important role for female labour supply in this respect. First,

\footnotetext{
${ }^{5}$ We use a model where families receive a fixed amount of income from female earnings given by
}

$$
\begin{aligned}
& y_{t}=\bar{P}_{t}^{\sigma_{\xi}^{2}}\left[y_{0} * \exp \left(\bar{h}_{t}^{\sigma_{\xi}^{2}}\right) * \exp \left(v_{t}\right) * \text { hours }-F_{t}\right] \\
& v_{t}=v_{t-1}+\xi_{t} \quad \text { where } \xi_{t} \sim N\left(-\frac{\sigma_{\xi}^{2}}{2}, \sigma_{\xi}^{2}\right)
\end{aligned}
$$

where $\bar{h}_{t}^{\sigma_{\xi}^{2}}$ and $\bar{P}_{t}^{\sigma_{\xi}^{2}}$ are the average human capital and participation rates of women of age $t$ in an economy with husband earnings variance equal to $\sigma^{2} . F_{t}$ is the fixed cost of working at age $t$.In Table 3 we use the low variance economy to calculate the exogenous income stream. 
additional uncertainty increases female participation rates, although this happens during the period of the life cycle when fixed costs do not play a large role. The effect on participation is greatest when borrowing (and hence consumption smoothing) is constrained. Second, the welfare loss caused by an increase in uncertainty is larger in the absence of the possibility of adjusting female labour supply. This effect is particularly pronounced in versions of the model where consumers have the possibility of borrowing and saving, suggesting a complementarity between labour supply and saving as insurance mechanisms.

The exercise we propose is not without limitations. First and foremost, we have not calibrated the level of uncertainty in a realistic fashion. Related to this issue, we have ignored the possibility that female and male earnings are correlated. Furthermore, we have focussed on permanent shocks and ignored temporary shocks. While we know that when households can borrow and save, most of these shocks are absorbed through savings, it would be interesting to explore more the cases in which households are prevented from borrowing. Finally, we have not considered explicitly unemployment risk. To the extent that unemployment is temporary, adjusting female participation is a crude way of providing insurance if there are costs of adjustment, and is likely to be used only when individuals have exhausted borrowing and saving opportunities.

Even with these limitations however, our exercise is useful for at least two reasons. First it provides a conceptual framework (admittedly not the only possible one) for thinking about female labour supply as an insurance mechanism. An interesting extension of our exercise would be to check the extent to which our conclusions are affected when one considers alternative mechanisms. Second, we have shown that, indeed, female labour supply can be used as an important chanel for absorbing earning shocks.

\section{References}

[1] Attanasio, O. and Davis (1996) "Relative Wages Movements and the Distribution of Consumption" Journal of Political Economy, 104 (6): 1227-1262.

[2] Attanasio, O.P., Low, H. and V. Sanchez-Marcos (2004) "Explaining changes in female labor supply" University of Cambridge working paper

[3] Attanasio, O.P. and G. Weber (1995) "Is Consumption Growth Consistent with Intertemporal Optimization?" Journal of Political Economy, 103 (6): 1121-57.

[4] Blundell, R., Pistaferri, L. and I. Preston (2004) "Partial insurance, information and consumption dynamics" IFS working paper W02/16.

[5] Eckstein, Z. and K. Wolpin (1989) "Dynamic labor force participation of married women and endogenous work experience" Review of Economic Studies 56: 375-390 
[6] Gruber, J. and Cullen, J.B. (2000) "Does Unemployment Insurance Crowd Out Spousal Labor Supply?", Journal of Labor Economics 18 (3): 546-572.

[7] Hotz, V.J. and R.A. Miller (1988) "An empirical analysis of life-cycle fertility and female labor supply" Econometrica 56(1): 91-118

[8] van der Klaauw, W. (1996) "Female labour supply and marital status decisions: a life-cycle model" Review of Economic Studies 63(2): 199-235

[9] Kotlikoff and Spivak (1981) "The Family as an Incomplete Annuities Market", Journal of Political Economy 89 (21): 372-391.

[10] Low, H. (2002) "Self-insurance and life-cycle savings and labor supply" Unpublished manuscript, University of Cambridge

[11] Lucas, R. (1987) Models of Business Cycles Basil Blackwell.

[12] Mincer, J. and S. Polachek (1974) "Family investment in human capital: earnings of women" Journal of Political Economy 82(2): 76-108

[13] Olivetti, C. (2001), "Changes in Women's Hours of Market Work: The Effect of Changing Returns to Experience". Unpublished manuscript, Boston University

[14] Pencavel, J. (1998) "The Market Work Behavior and Wages of Women: 1975-94." Journal of Human Resources 33(4):771-804.

[15] Pijoan, J. (2004) "Precautionary Savings or Working Longer Hours?". Unpublished manuscript, CEMFI.

[16] Rogerson, R. and Schindler, M. (2002) "The Welfare Cost of Worker Displacement", Journal of Monetary Economics, 1213-1234

[17] Storesletten,K., Telmer, C., and Yaron, A. (2001) "The Welfare Costs of Business Cycles Revisited: Finite Lives and Cyclical Variation in Idiosyncratic Risk", European Economic Review 45 (7): 1311-1339 